successional cheek-teeth. Such independent developments seem, however, in the highest degree improbable.

The fact that in the existing thylacine the epipubic bones do not ossify may perhaps be held to indicate that a similar condition obtained in the Miocene sparassodonts, although such a loss is improbable in these early forms, more especially as one of them is considered to have been partially arboreal. Be this as it may, it is quite clear (unless we again admit a series of independent developments) that the sparassodonts cannot be regarded as belonging to a grade of marsupials in which these bones had not yet been evolved, because we find them fully developed in the Oligocene opossums.

The most important argument of all against the marsupial nature of these Patagonian carnivores is, however, one derived from the nature of the enamel of their teeth, which does not appear to have come under the author's notice. According to the observations of $\mathrm{Mr}$. C. S. Tomes (Proc. Zool. Soc. London, I906, p. 45) the enamel of the sparassodont teeth is histologically identical with that of creodonts and modern carnivores, and quite unlike that of all marsupials.

Seeing, then, that sparassodonts, which are later in age than certain undoubted marsupials, differ from existing carnivorous marsupials as a whole in the minute structure of their dental enamel, by the lack of epipubic bones, the absence of unossified spaces in the floor of the skull, and apparently by the larger number of successional premolars, it seems improbable that they are really members of that group. On the other hand, they resemble creodonts in their complete palates, in the absence of epipubic bones, and to a great degree as regards the replacement of the cheek-teeth, while it is highly probable that many of the cranial characters referred to as being marsupial may really be primitive ones. The one essentially marsupial feature is the presence, in some cases, of four pairs of upper incisors.

On the whole, therefore, it seems advisable to regard the Patagonian carnivores as creodonts showing a tendency (it may or may not be parallelism) towards the marsupial type. That creodonts, sparassodonts, and carnivorous marsupials are, however, related groups, and that the former are not improbably the oldest and most primitive of all known mammals (perhaps directly descended in "Gondwanaland" from anomodont reptiles), appears almost certain. And it may further be suggested that these early creodonts have developed in one direction towards the sparassodont type, in a second towards the carnivorous marsupials, while in a third line they have developed into the modern Carnivora. Beyond this it seems at present impossible to go.

It should be added that the present writer was at one time of opinion that sparassodonts were marsupials.

R. L.

\section{THE GODS OF HEALING OF THE EGYPTIANS AND GREEKS.}

D R. R. CATON recently delivered a short course of lectures on the above subject in connection with the Institute of Archæology at the University of Liverpool. After referring to the works on medicine written by Athosis, the son of Menes, and also by the Pharaohs, Usaphais and Semti in very early times, he described briefly the cults of Isis, Serapis, Thoth, and I-em-hotep, and gave a short account of the temples in which the work of healing took place. Of these, quite the most important was the temple of I-em-hotep at Memphis. All these shrines of healing are destroyed, excepting the small temple of I-em-hotep on the island of Philæ. Dr. Caton referred to the large number of medicinal agents used by the Egyptians, and to the practice of incubation or temple sleep. In the temples of Isis and Serapis, and probably in the more important shrines of I-em-hotep, the sick slept in or adjacent to the temples, in the belief that the god would manifest himself to them or speak to them in dream or vision, and suggest the method of cure. Such dreams or visions were interpreted by the priest, and the treatment adopted was supposed to be founded in accordance with them. Sometimes no dream was vouchsafed, or no interpretation could be drawn from it bearing on the disease; in that case the priest did the dreaming. The priests of I-em-hotep had also to do with the embalming of the body, and, partly through this, they acquired a considerable knowledge of anatomy, and learned certain facts regarding the circulation of the blood. Some of the medical papyri contain remarkable details as to the bloodvessels and the movement of the blood; probably the Greeks obtained from them all the knowledge they possessed on this subject.

In Greece and Magna Græcia various gods and demigods were supposed to possess medical powers. Men Karon at Laodicea was a health god much in vogue in Asia Minor, and a large medical school was associated with his temple.

Apollo, Amynos, Asklepios, Hygeia, Amphiaraus, Trophonios, Aphrodite, and the Chthonic deities Pluto, Demeter, Persephone, and others of lesser importance were eminent for their health-giving efficacy in Greece. Of these, the cult of Asklepios was by far the most important. At numerous splendid temples, rich with the finest products of Greek art, the worship of the god and the cure of the sick were carried on for centuries.

Epidaurus was perhaps the most important of these shrines; it was a centre from which the cult was disseminated through other parts of Greece and the colonies. Trained priests, and also the sacred serpents, which were believed to be the incarnation of the god, were sent thence to carry on the work of healing in such places as Athens, Corinth, Delphi, Pergamon, Cnidos, Rhodes, Cos, and many other cities.

In all, incuhation was the initial step and the guide as to treatment. Probably the people would have had no confidence in the methods used but for the belief that the god himself had suggested them; even the priests themselves may in part have been believers. Many of the priests were physicians, who in the course of ages compiled much valuable information; they possessed useful methods of treatment in regard to rest, to diet, to the remedial use of exercise and of baths, and medicines. The ritual was beautiful and impressive, and their practice seems to have been humane in all respects except one. The god and his priests must have no dealings with death or with birth. If either were impending, the unhappr patient was at once expelled from the holy precinct. Not until the time of the Antonines were the special " houses of Birth and of Death " provided, external to the precinct for these two classes of sufferers.

At $\mathrm{Cos}$ the influence of Hippocrates seems to have been directed always towards the effacement of superstition and the founding of medicine on truth and fact alone. His influence seems to have had no effect as regards the practice of incubation, for it continued through Pagan and into Christian times.

As the East was Christianised the cult of Asklepios was the last to disappear, but the healing went on in the same manner (excepting that the sacred serpents seem to have vanished). The Panagia, or a Christian saint, took the place of Asklepios, and incubation went on unchanged. The practice spread over large parts of Europe, and was even to be found in England during the Dark Ages.

It still exists on many of the islands and on some of the shores of the eastern Mediterranean. Details of the ancient and modern practice of incubation are to be found in the writings of Dr. Rouse and Miss Hamilton, who have both devoted close attention to this curious usage.

An interesting feature of the life of these ancient health resorts was the provision made for the entertainment and amusement of the sick visitors. A great open-air theatre was always at their disposal, where the works of the Greek dramatists would wile away many an hour of weariness and languor.

In later times an Odeon, or music-hall, was sometimes provided. The races of the stadium and the exercises of the gymnasium and palæstra would be good for many of the youthful convalescents to take part in, and amusing for others to witness. The health temples were usually placed in elevated situations, where pure mountain breezes would invigorate the visitant, and pure, fresh water was

No. I95I, VOI. 75] 
abundant. Beautiful country scenery, as well as masterpieces of architecture and art of other kinds in the precinct, would aitract his attention, awaken his interest, and tend to prevent him dwelling too much in thought on his own ailments. There can be little doubt that the sick were in general much benefited by their residence at the Asklepieia of ancient Greece.

\section{THE SNOW-PEAKS OF RUWENZORI.}

THE paper read by the Duke of the Abruzzi at the special meeting of the Royal Geographical Society on January $\mathrm{I2}$, of which a short report was given in NATURE for January 17 (p. 282), has been printed in full
Mount Stanley Queen Margherita Peak
The paper as printed supplies information as to the basis for the determination of the heights of the snowpeaks, fourteen of which were climbed by the Duke. With one exception, they all depend on observations with the mercurial barometer referred to Bujongolo as a lower station, which agsain was linked with Fort Portal, and through this with Entebbe, by barometer readings as nearly simultaneous as possible. Some of the heights above Bujongolo were also fixed by Captain Cagni by vertical angles, the results agreeing closely with those of the barometer observations. The Duke's figures are mostly about roo feet to 200 feet in excess of those derived from Captain Behrens's triangulation, and it is possible that when the altitude of Fort Portal above the Victoria lake has been

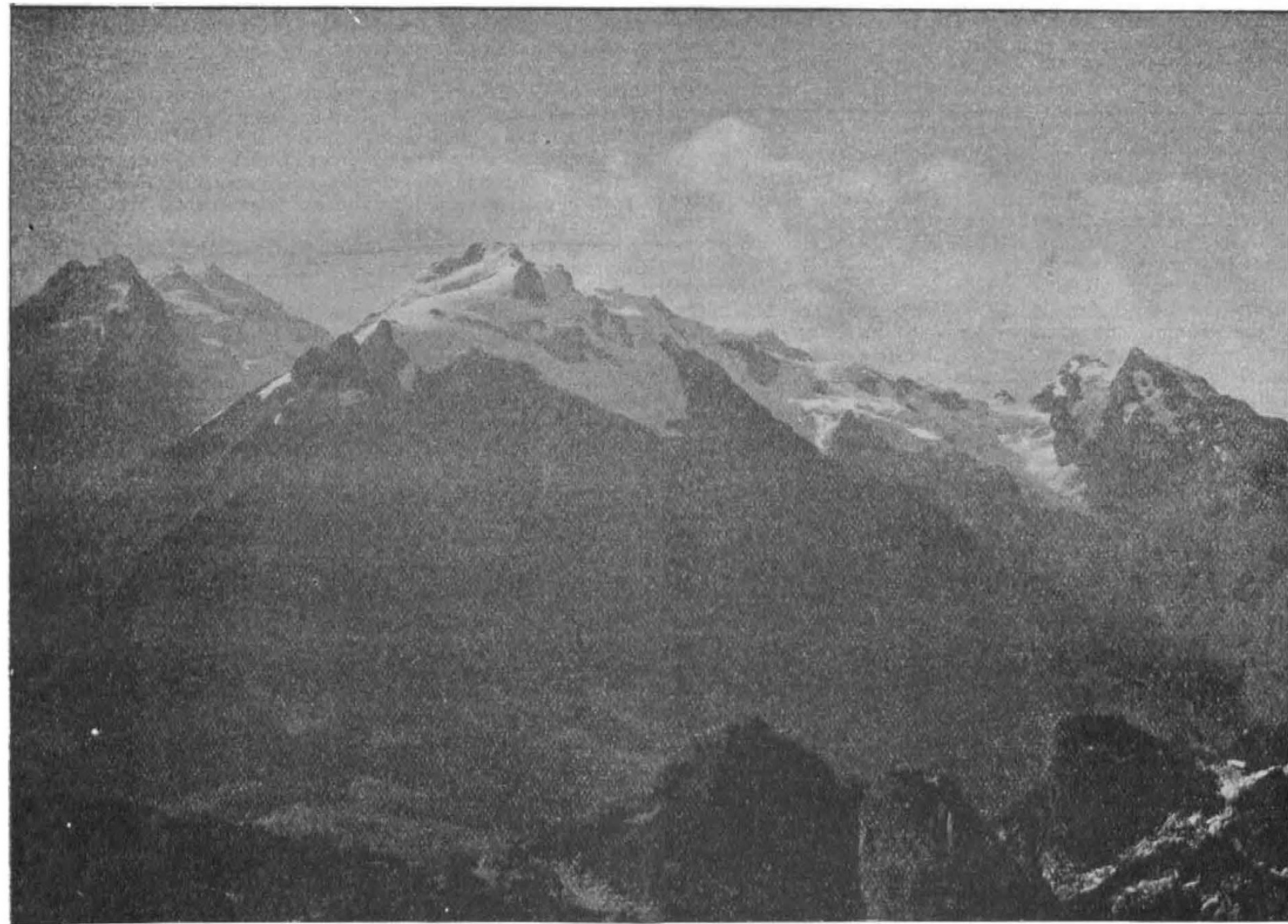

The Highest Feaks cf Ruwenzori.

Moore Gla'ier

in the February number of the Geographical Journal, accompanied by a small selection of Signor Sella's striking photographs. One of these, showing the highest summits of the range, we are enabled to reproduce herewith by the courtesy of the editor of that journal. The twin peaks in the background on the left are the culminating points of the whole range, named by the Duke after the queens of Italy and England. They belong to the group of peaks named by him Mount Stanley, while the remaining summits shown in the photograph form together the group to which the name Mount Baker is applied, the highest point of which is King Edward Peak (the most central in the picture). As is well shown, the two massifs (like the whole six which constitute the snowy portion of the range) are separated by a comparatively deep depression, to which the name Scott Elliot Pass has been given by the Duke. fixed trigonometrically, a small correction will have to be applied throughout. The general accordance in the heights of the six separate massifs is somewhat striking, none falling below 15,000 feet, while the highest point of all is only $\mathrm{x} 6,8 \mathrm{I} 6$ feet. None of the peaks offers any serious difficulties to the climber, for the Duke says that the obstacles met with during the ascent of the Queen Margherita peak could have been avoided by another route.

The Duke's conclusions as to the geological history of the range were summarised in our former article, but it may be added here that attention is directed to the probable existence of internal fractures traversing the whole range in a generally north-south direction, which would account for the separation of the several groups of summits. The general hydrographic system can be grasped from the

No. I95I, VOL. 75] 